\title{
The Interaction between Population Age Structure and Policy Interventions on the Spread of COVID-19
}

\section{Zhu Liu ( $\nabla$ zhuliu@tsinghua.edu.cn )}

Tsinghua University https://orcid.org/0000-0002-8968-7050

Hao Yin

Tsinghua University

Daniel Kammen

University of California, Berkeley

\section{Article}

Keywords: COVID-19, population age structure, policy Interventions

Posted Date: August 24th, 2020

DOI: https://doi.org/10.21203/rs.3.rs-57858/v1

License: (1) This work is licensed under a Creative Commons Attribution 4.0 International License.

Read Full License 


\section{Abstract}

COVID-19 has caused an unprecedented public health crisis and economic shock to the global economy. After months of worldwide pause, countries and cities are facing growing pressure to lift restrictions on economic activity. The optimal reopening strategy may vary significantly between cities depending on their demographics and social mixing. In this study, we explore the interaction between population age structure and various containment interventions in four cities with different age distributions that have been or are currently local epicenters of the epidemic. Our model quantifies that earlier interventions avoided an additional $13 \%, 58 \%, 70 \%$ and $86 \%$ of the infections in Los Angeles, New York, Daegu and Nairobi, respectively, compared to what has been observed in the four cities. Critically, we find that not only can social-distancing policies exhibit strong age-differential effects, but that even age-targeted interventions can have significant spillovers. Specifically, $50 \%$ reduction in the contact rates of population under 20 and older than 60 avoids $5 \%, 11 \%, 11 \%$ and $28 \%$ of infection among the elderly than the policy targeting the older adults alone in New York, Daegu, Los Angeles and Nairobi, respectively. In particular, to protect the elderly, it is essential to increase social distancing among the younger population, especially those under 20 years old. An older population structure results in a higher fatality risk while might decrease the infection risk. This is particularly critical as colleges and universities, in both cities and small towns, plan for on-campus activities with students drawn from a globalized pool. An older population structure results in a higher fatality risk while might slightly decrease the infection risk. A higher basic reproduction number exacerbates the influence of an old population structure on the fatality risk of the elderly. The significant differences in susceptibility and severity by demographic characteristics calls for targeted interventions to suppress the spread of COVID-19.

\section{Background}

The outbreak of COVID-19 triggered diverse and uncoordinated responses from countries across the world. By the beginning of July, some cities flattened the "infection curve" and slowly began reopening the economy. Uncertainties and rebounding risks of relaxing interventions in the post-epidemic era still challenge the global economy and public health. Critical lessons for how long social isolation, testing, and city lockdown must remain in place, as well as the need to guard against re-infection demand immediate access to models that can be ground-truthed by comparing model results and the emerging responses to policies already in place in diverse urban settings.

For the most hard-hit countries, such as the US, Italy and Spain, there are greater percentages of older population who are facing much higher risks of hospitalization and fatality due to changes of immune system and the impact of preexisting health conditions over time ${ }^{1,2}$. Studies have found that COVID-19 is an emergent disease of ageing ${ }^{3,4}$.

The high proportion of the old population might require much more resources in healthcare services and medical resources, which places a significant burden on the health care infrastructure of many ageing countries. However, quantitative analyses of such burden to the local healthcare system are limited. This 
gap in the literature presents challenges for cities and countries to adopt effective strategies to ease the spread of infections while recovering the economy. The significant differences in demographic characteristics of COVID-19 susceptibility and severity calls for targeted interventions to suppress the surge of the epidemic. Studies have emphasized the importance of incorporating demographic information in curbing the spread of the epidemic ${ }^{2}$. Important and critically needed modeling studies have explored the effects of different interventions, such as social distancing, school closing and citylockdown policies ${ }^{5-9}$. Social distancing has been recognized as one of the most effective mitigation strategies ${ }^{10,11}$. The effects of social distancing has been estimated using compartment model ${ }^{9}$, branching process model ${ }^{12}$ and reduced form econometric model ${ }^{13}$. However, most studies do not consider demographic variation in the effect of interventions on the total population. While some models have explored age-specific effects, they did not incorporate population movement. An important recent study by the Imperial College COVID-19 Response Team explored the impacts of public health interventions in 11 European countries ${ }^{14}$. Here we focus on individual cities where the policy steps are more homogeneous and can be well-described in the model we present and make available in this study. Understanding the effects of population age structure on the spread of the epidemic under various containment interventions enables policymakers to make effective decisions to relieve the pressure on healthcare systems without pausing the economy. By considering travelers' dynamics, we are also able to test the effects of border-closure and city-lockdown policies to inform decision makers with a full picture of potential outcomes before and after the reopening stage. In addition to social distancing, there are additional opportunities for countries to transition from stopping the economy. Strategies tailored to targeted age groups within the population are in an urgent need to protect public health and recover the economy.

In this study, we focus on four representative cities, New York, Los Angeles, Daegu and Nairobi, that reflected diversities in terms of socioeconomic environment, demographics and containment strategies. The findings obtained from the four cities are transferable to cities or countries with similar demographic and socioeconomic situations. The containment measures in the four cities and their effects varied significantly. As the world's most impacted nation, the number of infected cases in the United States (US) surged to 5 million by August 9, $2020^{15}$. New York, the most populous US metropolitan area, was once the epicenter and is now beginning to recover the economy. By contrast, Los Angeles, had a total number of infected cases accounting for fewer than $10 \%$ of that in New York in April but became the new epicenter by the time of writing. Many factors influenced such differences. The effectiveness of an intervention policy heavily depends on whether the policy is instructive for the public and if the population behaved accordingly. The rapid rise of infections in Los Angeles might be largely due to the reopening policy in May 2020 which resulted in higher a social mixing rate. Explanations for the rapid increase in the spread of COVID-19 have been discussed ${ }^{16,17}$. Compared with the containment strategy in the US overall, South Korea implemented a relatively faster and more effective testing regime, contact-tracing, and quarantining of infected cases without fiercely reducing the daily mobility. Detailed online instruction and clarification of requirements for isolation were widely disseminated online. Nairobi, as the capital city of Kenya, has a relatively younger population than the other three cities. Kenya also took a fast response 
since the first case was detected. However, recent reopening policy in Nairobi induced growing infected cases across the country. Overall, the four cities implemented measures of social distancing, travel restriction, school closure and personal hygiene. While South Korea and Kenya required people to wear face masks at the beginning of the outbreak, the US did not encourage people to wear face masks/face covering until April 3, $2020^{18}$. In addition, the quarantine policy in the US was not as strict as the one in South Korea and Kenya.

In addition to the policy responses for the general population, some policies also targeted the older population as they face higher risks than younger people. For instance, Los Angeles required peopled aged 65 and older to only leave home for essential activities ${ }^{19}$. While the US Centers for Disease Control and Prevention recommended specific measures for older adults ${ }^{20}$, the growing infected cases among younger people also endangered the elderly. The difference in the interaction of these non-pharmaceutical interventions and age structures of population might deviate the transmission rate of COVID-19.

In this study, we presented the age-specific effects of non-pharmaceutical interventions in the four cities by applying an age-specific and population-dynamic SEIR-HQD (susceptible-exposed-infected-recoveredhospitalized-quarantined-dead) model. We adapted our model from a single-age-group SEIR model ${ }^{21}$ to an age-specific model that is able to describe contacts and transmission patterns among the population from different age groups (Fig. 7). Details of our mathematical model and methods are provided in the Methods. Some studies have discussed the age-specific effects of social distancing, but the interaction of population age distribution and interventions with population movement remain unclear. Before the simulation, we first estimated the city specific basic reproduction number, $\mathrm{R}_{0}$, using observed infection incidence and serial interval data. The serial intervals in the four cities were fitted using a Markov Chain Monte Carlo (MCMC) algorithm. The age-specific transmission rates were calculated based on the social mixing characteristics. We assumed the effects of the time-series policy interventions, including school closure, working from home, reducing mobility, increasing quarantine rate and city lockdown, as well as the observed policy interventions were proportional to the city mobility and behavioral changes in each social mixing location. The strength of each policy is adjusted according to the local and national policy announcement and local mobility data. In addition to the specific interventions, we also tested the agespecific effects of intervention timing on the spread of COVID-19. To understand the influence of demographics on the effects of policy interventions, we simulated the spread of infection in New York with the age structures of the other three cities. Susceptible population, social mixing and transmission rates were adjusted according to the counterfactual population age structures.

We first present time-series reproduction number and the matrices of age-specific transmission rates in the four cities (Fig. 1). The counterfactual transmission matrices of different social distancing strategies are developed based on the social mixing information in New York as an example. Next, we modeled agespecific effects of three categories of social distancing, quarantine, and city lockdown policy responses in eight scenarios over a one-year period (Fig. 2). The age-differential effects of containment measures are identified to design policies for the targeted age groups of population. We further investigate the effects 
of implementing all the policy responses by one week earlier (Fig. 3) to assist policy response timing to avoid a second or third wave of reinfection. The time-series measures are inserted to the SEIR-HQD model on the date policy implemented and then we move the policy measures one week earlier to test the effects. For cities in the post-pandemic stage, opening the border and boosting the economy are major transition measures. To this end, we tested the age-specific risks of lifting restrictions on domestic and international travel, and the benefits of city-lockdown measures (Fig. 4). By applying counterfactual population age distributions for New York, we tested the influence of population age structure on the effectiveness of containment responses (Fig. 5). The contact matrices and transmission rates are adjusted with the counterfactual demographic data and the other parameters are maintained the same.

\section{Results}

\section{1 $\mathrm{R}_{\mathrm{t}}$ and age-specific transmission rates in four cities}

We estimated the time-series reproduction number in New York, Los Angeles, Daegu and Nairobi (Fig. 1). It shows that all the $R_{t}$ estimates in four cities decreased over time. $R_{0}$ is the basic reproduction number which assumes that the overall population is susceptible. The threshold of $R_{t}$ is 1 , which defines that the epidemic will be under control and die down if $R_{t}<1$. By averaging the first 30 days of $R_{t}$, the estimates of $\mathrm{R}_{0}$ were $3.60(3.16,4.12), 3.19(1.78,5.04), 3.75(2.66,5.16)$ and $2.53(1.44,3.93)$ in New York, Los Angeles, Daegu and Nairobi. In Fig. 1, we grouped the reported policy interventions in New York. Under the enhanced social distancing and testing policy interventions, the $R_{t}$ decreased below 1 after 50 days of the outbreak in New York. The $R_{t}$ values in Los Angeles decreased faster than New York but lifting the social distancing policy induced a rise in the $R_{t}$ since April. Daegu contained the epidemic and maintained $R_{t}$ below 1 between February and May, however relaxing the interventions resulted in a surge of reinfection and growing $R_{t} \cdot R_{t}$ in Nairobi decreased rapidly since the first case was reported, however the $R_{t}$ values remained higher than 1 which required Nairobi to implement stricter social distancing and quarantine strategy to contain the epidemic.

Applying $\mathrm{R}_{0}$ estimated in each city, we further generated the transmission rate matrices across 9 age groups. In addition to factors such as population density and social habits, the population age structure also influences transmission rates among different age group population. As shown in Fig. 1, the transmission rates were higher in young and middle age groups (under 60 years old) due to the higher contact rates and mobility compared with older age groups (60 years and older). Some studies argued that younger population are less infectious than older population since younger population tend to have higher chance of asymptomatic ${ }^{9}$, however, there is limited information on the infectiousness of asymptomatic cases and the incidence of them. Therefore, we assume that the transmission happens when they are presymptomatic and symptomatic. Daegu has the highest transmission rates and Nairobi has the lowest transmission rates compared with the other three cities. When school closure is implemented in New York, the age-specific transmission rates decreased $50 \%$ of transmission rates for 
population aged $10-19$. If New York city implemented school closure, $50 \%$ working from home, and $50 \%$ reduction in mobility could effectively control the transmission rates under 0.1 in all age groups.

2.2 The age-specific effects of different interventions on the spread of COVID-19

Figure 2 presents the effects of each intervention category on the containment of infection over a year period in the four cities simulated starting with 2 infected cases per million incidence implementing interventions of school closure (Intervention A), 50\% (Intervention B) and 80\% working from home (Intervention C), 50\% (Intervention D) and 80\% reduction in other mobility (Intervention E), 10\% quarantine rate (Intervention F), city lockdown (Intervention G) and a combined strategy of school closure (Policy A), $50 \%$ working from home (Intervention B), 50\% reduction in other mobility (Intervention D) and 10\% quarantine (Intervention F) and city lockdown (Intervention G) interventions (Intervention H). By adopting additional social distancing among targeting population, we generated the effects of age-targeted interventions (Figure 2b-2c). The effects of each policy intervention in the four cities are defined as the proportion of the avoided infection with interventions to the infected cases without interventions. It shows that school closure attenuates transmission risks among population under 20 years old. The school closure policy is most effective in Daegu and Los Angeles compared with the Nairobi and New York cities. In contrast, working from home will mostly influence people aged 20 to 60 years old and avoid $10 \%-30 \%$ and $15 \%-45 \%$ of infection in the four cities with $50 \%$ and $80 \%$ of people working from home. Quarantine intervention has relatively even influence on the spread of COVID-19. The city-lockdown policy will avoid most infected cases in New York city and least cases in Nairobi. If policy interventions are implemented over one-year period, it shows that a combined strategy will effectively flatten the curve of infection in Los Angeles, Daegu and Nairobi cities (Figure 2a in Supplementary). However, New York might need to implement stricter social distancing than the other three cities to fully contain the epidemic. After implementing social distancing among the senior adults (Figure $2 b$ ), the avoided infection among the older population increased $10 \%-40 \%$ of the infection without intervention in the four cities. However, targeting policy in the older population showed limited impacts on reducing the infection in the other age groups. In addition, we added the social distancing in the young population under 20 years old to the above intervention scenarios in Figure $2 \mathrm{~b}$. It demonstrated substantial benefits among the targeted population while also demonstrated significant spillover benefits in the middle-aged population (Figure 2c).

\subsection{Age-specific benefits of intervention timing}

Figure 3 shows the simulated infected cases of COVID-19 under 1-week earlier interventions compared with the timing of their current policy interventions that were already implemented in the four cities. An earlier intervention avoided 13\%, 58\%, 70\% and 86\% infection related to COVID-19 in Los Angeles, New York, Daegu and Nairobi. The earlier intervention benefited population aged 50 years and older by 4 and 8 percentage points more than younger population in Daegu and New York. While the age-specific effects are relatively even in the other two cities. The earlier intervention strategy also mitigated the 
overwhelming requirement of hospital beds. Moving intervention earlier could help flatten the curve to certain degree depending on the effectiveness of containment strategies.

\subsection{Effects of population movement}

To understand the impacts of population movement on the spread of epidemic, we conducted a sensitivity test on the scale of population dynamics inbound and outbound the four cities. The results showed that the increasing movement will result in substantial growth of infection in New York, Daegu and Nairobi. Nairobi has more inbound travelers than outbound (Table 1). Therefore, opening border or lifting travel restriction will induce higher risk of infection in Nairobi. In the study period of this analysis, the international/domestic incidence of infection was higher than the incidence of the studied cities, therefore, the results demonstrated the higher mobility will result in higher infection. However, if the city incidence is higher than the international incidence or domestic incidence, the opening up policy might decrease the infection inside the city whereas result in rapid spread of infection in other cities or countries. In terms of the age-specific effects, the increase of domestic and international travlers will result in rise of infection among the younger population (under 60) than the senior adults (Fig. 4b).

\subsection{Effects of population age structure}

We also tested the effects of population age structure on the spread of COVID-19. We simulated the spread of infection in New York (ageing rate, the proportion of population aged 65 and older: 0.09) applying the age-structure data in Los Angeles (ageing rate: 0.07), Daegu (ageing rate: 0.05 ) and Nairobi (ageing rate: 0.02 ). The ageing rate refers to the proportion of population aged 65 and older. Both the contact matrices and transmission rate in New York city were adjusted with the age structure in the other three cities with younger population. Figure $5 \mathrm{a}-5 \mathrm{~b}$ represents the daily infection and cumulative dead cases over 365 days in New York $\left(R_{0}=4.5\right)$. The infection will increase by $0.067,0.022$ and 0.004 when the simulation was conducted using age structures information from Los Angeles, Daegu and Nairobi are applied, respectively (Fig. 5c-5d). By contrast, a younger population will avoid $0.085,0.154$ and 0.420 dead cases in Los Angeles, Daegu and Nairobi compared with the death with age structure in New York.

We further analyze the influence of $\mathrm{R}_{0}$ on the spread of COVID-19 due to the change of population age structure. It is straightforward that the infection and dead cases increase with the growth of $R_{0}$ (Fig. 5a$5 b)$. While little knowledge on how the change of $R_{0}$ affects the spread of COVID-19 under different population age distributions. We simulated the spread of infection in New York with different $\mathrm{R}_{0}$ values using the counterfactual age structures in Los Angeles, Daegu and Nairobi. If New York city has a younger population as Nairobi, it will avoid $0.317,0.382,0.420$ and 0.438 deaths when $R_{0}$ is $2.5,3.5,4.5$ and 5.5, respectively. It indicates that the increase of $R_{0}$ will exaggerate the impacts of an older age structure on the spread of COVID-19. On the contrary, New York city with age structure in Nairobi will result in $-0.3 \%,-0.3 \%, 0.4 \%$ and $1.7 \%$ more cases of infection. In Table $5 a$ in the Supplementary, the agespecific transmissiblity will decrease when the population is younger, whereas the age-specific transmission rates after adjusted the contact matrices increase for population in certain age groups. 
Specifically, if New York city has a younger population as Nairobi, the transmission rates under 20 years old will increase $17 \%-80 \%$; if assuming population age structure in New York as Los Angeles, the transmission rate under 40 years old will grow by $2 \%-14 \%$; with Daegu's age structure, the transmission rates in New York city will increase by $7 \%-18 \%$ among population aged 40 to 70 years old. Therefore, the infection of COVID-19 might slightly increase or decrease depending on the younger level of susceptible population. However, in all three younger age strucutures, the infection and deaths among older population will decrease.

\section{Discussion}

We developed, documented, and provided an open source model which we utilized to examine the effects of different intervention strategies as nations manage risks to different age groups, and as sub-national regions work to curb the spread of COVID-19, and avoid the risks of a second reinfection wave. We tracked and modeled interventions in Daegu, South Korea, Nairobi, Kenya, and in Los Angeles and New York in the USA, to capture the effectiveness of these interactions between different public health interventions and population demographics by incorporating dynamic population movement. On top of the containment measures targeting to the general population, we designed the interventions targeting to people in different age groups and tested the effectiveness of such measures. In addition, we explored the age-specific effects of intervention timing, population movement on the spread of COVID-19 to inform reopening strategies for cities were past the first wave of the epidemic. By comparing the infection and fatality using counterfactual demographic information in different cities, we estimated the influence of population age structure on the effectiveness of intervention strategies.

Our study illustrates that age-targeted policy interventions are especially effective and show significant benefits to the rest of population. While most policy interventions targeted the general population or the older adults, our simulation finds that social distancing targeting both the older and younger population are the most effective and shows spillover effects without fully pausing the economy (the middle-aged population might still work with protection). Our results suggest that increasing social distancing among population under 20 is as much important as the measures to protect the older adults. However, some states in the US and many other countries opened or planned to open schools, which might not only threaten the health of the younger population but also endanger lives of the senior adults. According to our results, we do not recommend countries without flattening the curve of infection to reopen schools or reopen without social quarantine and face covering.

Early interventions averted substantial infection and relieve the pressure on the medical resources. The border closure and city lockdown showed substantial benefits to avoid the spread of infection compared with single social distancing strategy. The city lockdown strategy is more effective if the city has a higher rate of inbound and outbound travelers. We also find that the city-lockdown policy benefits the younger and middle-aged population the most due to their higher mobility. Our results suggest that strict social distancing and temporal city-lockdown measure should be in action when the new cluster or community cases are detected. Any delay of these interventions might cause a surge of reinfection. Also, full 
deconfinement of all interventions will result in a quick rebound effect since the high incidence rates of COVID-19 globally.

An older population age structure exaggerates the fatal impacts of COVID-19, whereas a younger population might result in higher risks of infection due to their higher contact rates compared with the senior adults. Our results demonstrated that maintaining social distancing in the younger population has significant spillover effects on the other age groups of population. A combined social distancing targeting both young (under 20 ) and the older (older than 60 ) population significantly improve the effects of each policy intervention. Therefore, the cities with an older population should protect the older people by not only restricting activities of the older population but also confining the activities of the younger ones.

Despite the limitations, we concluded some policy guidelines for each city to facilitate the curbing or reopening interventions. The current opening-up policies in California ${ }^{22}$ might result in more infected cases at this stage of active cases. Although schools might remain virtual in New York, Los Angeles and Nairobi, there is no specific policy to warn children and young people to stay social distancing as their exposure to the COVID-19 will be likely to affect the middle-aged and older adults. Recent Children and COVID-19 data report showed that there were 338.9 thousands of children were tested positive for COVID19 in the US ${ }^{23}$. It is urgent to restrict gatherings and keep social distancing among the young while also protect the old population with community support on essential needs in daily life. In addition, there is no strict quarantine and travel restriction in most states of the US, which might result in more domestic import and export cases in the US. It will avoid substantial infection in the Los Angeles and New York if domestic travelers are quarantined for 14 days or a health test that shows the traveler is healthy. Recently, the US State Department lifted "Do Not Travel” advisory on August 4, 2020. Although there were only 22 countries opened or opened with restrictions to the US travelers at that moment ${ }^{24}$, some countries, such as Kenya and Rwanda, were planning to reopen the border to tourists. Thus, reopening and the lifting travel advisory will impose higher risks to the spread of COVID-19 cases in these nations. Due to the pressure of economy, Kenya started to implement subtle reopening policy in businesses, whereas Kenyans came back to life by ignoring the risks of COVID-19, which increased the risks of growing infected cases and pressure on the medical system. For Kenya, it is even more important to restrict the mobility and social mixing among the younger population. Daegu also suffered from designing proper reopening strategies. The cluster infection of the nightlife clubs alerted South Korea that it is not the time yet to reopen public gathering establishments. South Korea slowly reopened schools in May by requiring students and teachers to wear facemask with a strict social distancing order. The successfully containing and reopening experience in South Korea might also be good examples for other countries follow or adjust according to the local situation of infection. All the four cities should implement strict country/cityborder check for travelers and quarantine more infected cases. The quarantine intervention is based on the effective testing system and the knowledge of epidemiological survey for the contact tracing. A digital contact tracing tool should be adopted to reduce substantial workload pressure to the medical staff, or the travelers should keep a track on the persons with close contacts each day. We showed that it was 
possible to contain the pandemic with strategy of high quarantine rate together with moderate social distancing and city lockdown (or travel restriction with mandatory self-quarantine), which could largely avoid the costly impacts on the national economy.

Our study has several limitations. In our model, the social distancing strategy is based on the contact matrices developed in national level. We adjusted the contact matrices according to the population density to the city-specific data. This might introduce uncertainties in the estimates of transmission rates. The policy data were collected from government announcement or public sources that showed little knowledge on the possible effectiveness to the infection. Therefore, we adjusted the social distancing effects in various locations based on daily mobility data obtained from Google mobility reports ${ }^{25}$. The mobility data might not fully tell the change of contact rates in the population. The population travel data were averaged from monthly or annual traveler statistical database, which might introduce uncertainties in the effects of population movement. Therefore, we conducted sensitivity test of the population movement on the outcomes of infection. Our model is further constrained by adopting non-localized parameters in each city. This is restricted by current incidence data did not tell the age-specific information, which hindered the possibility to evaluate the age-specific parameters in each city. Since there was no age-specific fatality rates in each city, we adopted the age-specific fatality of China in four cities that was adjusted for censoring demographic information without the consideration of the medical capacity and facility information ${ }^{1}$. In addition, other environmental factors, such as air pollution, temperature and humidity, might have impacts on the transmission rate of COVID-19 geographically 26 , but the quantitative effects of these factors were not clear yet ${ }^{27,28}$. A unified age-specific fatality rate might over- or underestimate the estimates of deaths in the four cities.

\section{Materials And Methods}

Traveler data

We stratified each population into 9 age groups by a 10-year band, with the last age group set as those 80 years and older. We simulated both natural population dynamics (birth and death rates) and population movement due to inbound and outbound travelers in each city. In this study, we collected inbound international inbound and outbound traveler statistical data from multiple global and local statistical sources ${ }^{29-33}$. For the domestic inbound and outbound travelers statistical data, we retrieved from local news and travel department websites ${ }^{32-37}$. The average daily inbound and outbound travelers from international and domestic sources before the outbreak of COVID-19 are listed in Table 1. The daily change of international travelers in Daegu and Nairobi were adjusted according to the daily global mobility data, and the daily change of international travelers in New York and Los Angeles were adjusted according to the monthly change of I-94 arrivals data ${ }^{38}$. We adjusted the daily domestic travelers according to the daily change of mobility data from Google mobility reports ${ }^{25}$. 
Table 1

Daily import and export travelers in the four cities before the outbreak of COVID-19

\begin{tabular}{|lllll|}
\hline Travelers & New York & Los Angeles & Daegu & Nairobi \\
\hline Domestic import & 154637 & 75249 & 31085 & 1117 \\
\hline International import & 13658 & 11578 & 2289 & 2773 \\
\hline Domestic export & 162450 & 77173 & 31176 & 931 \\
\hline International export & 13231 & 11340 & 3752 & 361 \\
\hline
\end{tabular}

The domestic and international incidences of COVID-19 were estimated using daily infected cases divided by the total number of travelers:

$$
\begin{aligned}
\text { i. } \theta_{t} & =\frac{i . I_{t}}{i . T} \\
\text { d. } \theta_{t} & =\frac{d . I_{t}}{d . T}
\end{aligned}
$$

where i. $\theta_{\mathrm{t}}$ and d. $\theta_{\mathrm{t}}$ are global and domestic incidence of COVID-19 infection in day $\mathrm{t}$, and $\mathrm{i} . \mathrm{I}_{\mathrm{t}}$ is global daily infected cases in day $t$, and d. $I_{t}$ is domestic daily infected cases in day t. Both global and domestic infected cases were adjusted with a 7-day moving average. The estimated incidence rates were adjusted to age-specific incidence rates according to the global tourism age structure and country age structures.

\section{Population mobility}

We retrieved population mobility data from Google Covid-19 community mobility reports ${ }^{25}$. Figure 6 shows the change of mobility in each city since the outbreak of COVID-19. The mobility in working, other activities and school substantially dropped between march and mid-April in New York, Los Angeles and Nairobi. By contrast, Daegu did not show much reduction in terms of any category of mobility. The average mobility increased after mid-April due to the opening up policy in the US. From the mobility data, we can also tell that Nairobi started loosening their social distancing and working-at-home policies since April. The mobility of home increased since the intervention strategies were implemented, which might indicate growing contact rates at home. The time-series of contact matrices were adjusted by the change of daily change of mobility.

SEIR-HQD model framework

In this study, we adapted an SEIR model to an age-specific SEIR-HQD model for a period of 365 days. SEIR-HQD model considers 7 states of infection including susceptible (S), exposed (E), infectious (I) and recovered (R), hospitalized (H), quarantined (Q) and dead (D). The SEIR-HQD model incorporates the age structure, birth rates and death rates dynamics of the affected population in Daegu, New York, Los Angeles and Nairobi. 
Figure 7 Schematic framework of SEIR-HQD epidemic model "S = Susceptible, refers to the full city population", "E = Exposed, refers to infected but not infectious yet", "I = Infected, refers to population who are infected and infectious", " $R=$ Recovered, refers to the population who are recovered", " $Q=$ Quarantined, refers to the population who are quarantined", " $\mathrm{H}=$ Hospitalized, refers to people who are hospitalized, " $D$ = Dead, refers to the population who are dead infected". ITs and ETs refer to the imported and exported travelers who are susceptible, respectively. ITe and ETe refer to the imported and exported travelers who are exposed, respectively. ITi and ETi refer to the imported and exported travelers who are infected, respectively. $\nu$ is the birth rate per thousand population, $\mu$ is the death rate of population, $\beta$ SI refers to the infection force, $\sigma$ is incubation rate, $\gamma$ is recover rate, $\omega$ is the death rate of infected population, $\phi$ is the hospitalization rate, $\rho$ is quarantine rate.

Mathematical model and parameters setting

When the susceptible populations are exposed to infectious individuals, a percentage then transition into infected status at a given probability defined by an age-specific transmission rate. After the incubation period, the exposed population then become infectious, but if they are quarantined, we assume that they do not impact susceptible individuals in the next generation. For those who are infectious, given the hospitalization rate of infectious cases, we further calculate the number of people who are in need of further medical care in the hospital. Our model also simulates the quarantine of individuals and hospitalized cases are sub-states of infected cases that will not cause a secondary infection. The quarantine individuals might also become hospitalized. The epidemic evolution model is described as follows: 


$$
\begin{gathered}
\frac{d S_{i, t}}{d t}=\frac{v}{n} \sum_{i=1}^{n} \operatorname{pop}_{i}-\beta_{i, t} \frac{I_{i, t}-H_{i, t}-Q_{i, t}}{p o p_{i}} S_{i, t}-\mu_{i} S_{i, t}+\left(i . I T_{i, t}+d . I T_{i, t}\right) *\left(1+\left(1+\frac{1}{\sigma}\right)\right) * i . \theta_{i, t} \\
-\frac{\left(i . E T_{i, t}+d . E T_{i, t}\right)}{p o p_{i}} \times S_{i, t} \\
\frac{d E_{i, t}}{d t}=\beta_{i, t} \frac{I_{i, t}-H_{i, t}-Q_{i, t}}{p o p_{i}} S_{i, t}-\sigma E_{i, t}-\mu_{i} E_{i, t}+\frac{i . I T_{i, t}}{\sigma} * i . \theta_{i, t}+\frac{d . I T_{i, t}}{\sigma} * d . \theta_{i, t}-\frac{i . E T_{i, t}+d . E T_{i, t}}{p o p_{i}} * E_{i, t} \\
\frac{d I_{i, t}}{d t}=\sigma E_{i, t}-\gamma_{i} I_{i, t}-\mu_{i} I_{i, t}-\omega_{i} I_{i, t}+i . I T_{i, t} * i . \theta_{i, t}+d . I T_{i, t} * d . \theta_{i, t}-\frac{i . E T_{i, t}+d . E T_{i, t}}{p o p_{i}} * E_{i, t} \\
\frac{d H_{i}}{d t}=\varphi_{i, t}\left(I_{i, t}-H_{i, t}\right)-\omega_{i} H_{i, t}-\gamma_{i} H_{i, t}-\mu_{i} H_{i, t} \\
\frac{d D_{i, t}}{d t}=\omega_{i} I_{i, t} \\
\frac{d Q_{i, t}}{d t}=\rho\left(I_{i, t}-Q_{i, t}-H_{i, t}\right)-\varphi_{i} Q_{i, t}-\gamma_{i} Q_{i, t}-\omega_{i} Q_{i, t}-\mu_{i} Q_{i, t} \\
\frac{d R_{i, t}}{d t}=\gamma_{i, t} I_{i, t}-\mu_{i} R_{i, t}
\end{gathered}
$$

$S_{i, t}$ is the susceptible population in age group $i$ on day $t$,

$v$ is the birth rate per thousand population,

$\mu_{i}$ is the death rate of population in age group $i$,

$i . I T_{i, t}$ and $d . I T_{i, t}$ are the international and domestic imported travelers,

i. $E T_{i, t}$ and $d . E T_{i, t}$ are the international and domestic exported travelers,

i. $\theta_{i, t}$ and $d . \theta_{i, t}$ are the incidence of infected cases in the international and domestic travelers, respectively,

$n$ is the number of age groups, $\operatorname{pop}_{i}$ is the number of population in age group $i$,

$\beta_{i, t}$ is transmission rate, defined as the probability of infection between a susceptible and infected individual,

$I_{i, t}$ is the infected people in age group $i$,

$E_{i, t}$ is the exposed population in age group $i$,

$\sigma$ is the daily probability of an exposed individual becoming infectious, which equals to $1-\exp \left(-\frac{1}{d_{\text {inc }}}\right)$,

where $\mathrm{d}_{\text {inc }}$ refers to duration of average incubation time,

$\rho$ is quarantine proportion of exposed individuals,

$\gamma_{i, t}$ is the probability of an infected individual that recovers during the infectious duration $\mathrm{d}_{\text {inf }}$,

so that $\gamma_{i, t}=1-\exp \left(-\frac{1}{\mathrm{~d}_{\text {inf }}}\right)$,

$\varphi_{i, t}$ is the hospitalization rate in age group $i$,

$\omega_{i, t}$ is the fatality rate of infected individuals,

$Q_{i, t}$ is the number of individuals that are quarantined,

$R_{i, t}$ is the number of infected individuals who recover.

The parameters involved in the model are obtained from literature and are presented in Table 2.

Table 2

Parameters in the age-specific SEIR-HQD model

Parameters Value Reference

Basic reproduction Varies by city, see Appendix 1. Estimated in this study number $\mathrm{R}_{0}$

Transmission rate

Average incubation

period, $\mathrm{d}_{\text {inc }}$

Average duration of infection, $\mathrm{d}_{\text {inf }}$

Initial number of infected, $I_{0}$

Hospitalization rate, $\varphi_{\text {it }}$

Quarantine rate, $\rho$

$0 \%-50 \%$

7-11 days (assume growing

by age)

Varies by age, see Appendix 1. Estimated in this study

5.8 days $(4.8-6.8)$

Backer et al (2020)

2 cases per million in four cities

Varies by age, see Appendix 1

Fatality rate, $\omega_{i, t}$
Varies by age, see Appendix 1 .
Ferguson et al (2020) and Verity et al (2020)

Cao et al (2020) and Bi et al (2020)

Assumed in the study

Assumed in scenarios 
$\mathrm{R}_{\mathrm{t}}$ estimation

To simulate the spread of COVID-19 in different policy packages, we estimated the location-specific reproduction number, $R_{t}$, with serial interval data and incidence rates over time in the four cities. $R_{t}$ is the average number of secondary cases over the total infected individuals at certain time ${ }^{42}$. The serial interval data was retrieved from Du et al (2020). We assume a gamma prior distribution for serial interval using Bayesian statistical inference based on the above transmission estimation framework. After a 1000 burn-in, we run 15,000 iterations and sampled every 100th step via Markov Chain Monte Carlo simulation over a 7-days evaluation window and generated serial interval from the beginning of the outbreak to July $1,2020 . R_{t}$ is estimated using Wallinga and Teunis approach ${ }^{44} \cdot R_{0}$ in each city is estimated using the average value of $R_{t}$ over the first 30 days since the outbreak time.

Age-specific transmission rates

The transmission rate differs from the location, population mobility and contact probability. Therefore, we calculate the transmission rate matrix based on contact matrices in different location settings at country level. We first adjusted the contact matrices by age-specific population, the more population in certain age group, the higher probability of this group population gets in contact with one in other age groups. The contact matrices that were developed in Prem et al (2017) depend on the national population density. At city-level contact matrices, we further adjusted the contact matrix data by weights of population density in each city over the national average.

$$
\begin{gathered}
\mathbf{C}_{i, j}^{p o p}=\mathbf{C}_{i, j} \times \text { prop prop }_{i}^{p o p} / \text { rrop }_{j}^{\text {pop }} \\
\operatorname{det}\left(\mathbf{C}_{i, j}^{\text {pop }}-\lambda \boldsymbol{I}\right)=0 \\
\tau_{i}=\frac{R_{0}}{\max (\lambda) \times \mathrm{d}_{i n f}{ }^{T}} \\
\boldsymbol{\beta}=\tau_{i} \times \mathbf{C}^{\text {pop }}
\end{gathered}
$$

where ${ }^{i}$ and $i$ represent age groups, ${ }^{\text {pop }}$ is contact matrix in each city, ${ }^{\text {prop }}{ }_{i}^{\text {pap }}$ is the proportion of population in age group ${ }^{i}$ to the total population in a city, ${ }^{\tau_{i}}$ is transmissibility, which is defined as the transmission probability of a contact between an infectious individual with a susceptible one, $R_{\diamond}$ is the basic reproduction rate, and $\boldsymbol{\beta}$ is the transmission rate matrix among individuals in different age groups. Transmission rate indicates the rate of infectious cases infect secondary cases in certain age-group population, which is the product of transmissibility and contacts.

Scenario design for interventions and the timing of policy action

Applying the SEIR-HQD model, we designed two sets of scenarios to explore: 1) the age-specific effects of policy interventions, 2) the effects of age-targeting policy intervention, and 2) the effectiveness of policy 
action at different time points since the diagnosis of the first case.

For the age-specific effects, we designed 8 scenarios that tested school distancing, reduction in other mobility, increasing quarantine rates, city lockdown and a mixture policy package (Table 3 ). The city lockdown intervention refers to both inbound and outbound international travelers and domestic travelers are prohibited to travel during the lockdown period.

Table 3

Scenario design for age-specific effects analysis.

\begin{tabular}{|llllll|}
\hline $\begin{array}{l}\text { Intervention } \\
\text { Scenario }\end{array}$ & $\begin{array}{l}\text { School } \\
\text { closure }\end{array}$ & $\begin{array}{l}\text { Working from } \\
\text { home }\end{array}$ & $\begin{array}{l}\text { Reduction in other } \\
\text { mobility }\end{array}$ & $\begin{array}{l}\text { Quarantine } \\
\text { rate }\end{array}$ & $\begin{array}{l}\text { City } \\
\text { lockdown }\end{array}$ \\
\hline Scenario A & $100 \%$ & $0 \%$ & $0 \%$ & $0 \%$ & $0 \%$ \\
\hline Scenario B & $0 \%$ & $50 \%$ & $0 \%$ & $0 \%$ & $0 \%$ \\
\hline Scenario C & $0 \%$ & $80 \%$ & $0 \%$ & $0 \%$ & $0 \%$ \\
\hline Scenario D & $0 \%$ & $0 \%$ & $50 \%$ & $0 \%$ & $0 \%$ \\
\hline Scenario E & $0 \%$ & $0 \%$ & $80 \%$ & $0 \%$ & $0 \%$ \\
\hline Scenario F & $0 \%$ & $0 \%$ & $0 \%$ & $10 \%$ & $0 \%$ \\
\hline Scenario G & $0 \%$ & $0 \%$ & $0 \%$ & $0 \%$ & $100 \%$ \\
\hline Scenario H & $100 \%$ & $50 \%$ & $50 \%$ & $10 \%$ & $100 \%$ \\
\hline
\end{tabular}

We also reviewed the policy actions in four cities from the first case detected to July 1, 2020 (SuFigure 2). We followed the real policy actions to simulate the business-as-usual scenarios in the four cities. Then we move each strategy 1 week earlier to see the effects of early actions.

\section{Declarations}

\section{Declaration of interests}

We declare no competing interests.

\section{Open Access Code and Data sharing}

The COVID-19 incidence data used in this study is extracted from Johns Hopkins University ${ }^{15}$, the citylevel time-series mobility data were extracted from Google mobility reports ${ }^{25}$, the contact matrices database is retrieved from Prem et al (2017), the implemented policy information was collected from government reports and APAPS COVID-19 database ${ }^{46}$ and the travel data were extracted from multiple sources that are listed in the references. The modeling code and estimation process are available online at https://github.com/HaoYinV/SEIR-HQD and http://rael.berkeley.edu. 
Acknowledgements

HY was funded by the National Natural Science Foundation of China (grant 71904104) and the China Postdoctoral Science Foundation (grant 2019M650726). ZL acknowledges funding from Qiushi Foundation, the Resnick Sustainability Institute at California Institute of Technology and the National Natural Science Foundation of China (grant 71874097 and 41921005). DMK gratefully acknowledges the support of the Zaffaroni Family Foundation, the Karsten Family Foundation, and US NSF CyberSEES Grant \#1539585 and NSF InFEWS grant DGE \#1633740.

\section{References}

1. Verity, R. et al. Estimates of the severity of coronavirus disease 2019: a model-based analysis. Lancet Infect. Dis. (2020). doi:10.1016/S1473-3099(20)30243-7

2. Dowd, J. B. et al. Demographic science aids in understanding the spread and fatality rates of COVID19. Proc. Natl. Acad. Sci. U. S. A. (2020). doi:10.1073/pnas.2004911117

3. Santesmasses, D. et al. COVID-19 is an emergent disease of aging. medRxiv 2020.04.15.20060095 (2020). doi:10.1101/2020.04.15.20060095

4. Banerjee, A. et al. Estimating excess 1-year mortality associated with the COVID-19 pandemic according to underlying conditions and age: a population-based cohort study. Lancet (2020). doi:10.1016/S0140-6736(20)30854-0

5. Wu, J. T., Leung, K. \& Leung, G. M. Nowcasting and forecasting the potential domestic and international spread of the 2019-nCoV outbreak originating in Wuhan, China: a modelling study. Lancet (2020). doi:10.1016/S0140-6736(20)30260-9

6. Bayham, J. \& Fenichel, E. P. Impact of school closures for COVID-19 on the US health-care workforce and net mortality: a modelling study. Lancet Public Heal. (2020). doi:10.1016/S24682667(20)30082-7

7. Ferguson, N. M. et al. Impact of non-pharmaceutical interventions (NPIs) to reduce COVID-19 mortality and healthcare demand. Imperial.Ac.Uk (2020). doi:10.25561/77482

8. Tian, H. et al. An investigation of transmission control measures during the first 50 days of the COVID-19 epidemic in China. Science (2020). doi:10.1126/science.abb6105

9. Prem, K. et al. The effect of control strategies to reduce social mixing on outcomes of the COVID-19 epidemic in Wuhan, China: a modelling study. Lancet Public Heal. (2020). doi:10.1016/s24682667(20)30073-6

10. Leung, K., Wu, J. T., Liu, D. \& Leung, G. M. First-wave COVID-19 transmissibility and severity in China outside Hubei after control measures, and second-wave scenario planning: a modelling impact assessment. Lancet (2020). doi:10.1016/S0140-6736(20)30746-7

11. Vahia, I. V. et al. COVID-19, Mental Health and Aging: A Need for New Knowledge to Bridge Science and Service. Am. J. Geriatr. Psychiatry (2020). doi:10.1016/j.jagp.2020.03.007 
12. Hellewell, J. et al. Feasibility of controlling COVID-19 outbreaks by isolation of cases and contacts. Lancet Glob. Heal. 8, e488-e496 (2020).

13. Hsiang, S. et al. The effect of large-scale anti-contagion policies on the COVID-19 pandemic. Nature (2020). doi:10.1038/s41586-020-2404-8

14. Flaxman, S. et al. Report 13: Estimating the number of infections and the impact of nonpharmaceutical interventions on COVID-19 in 11 European countries. (2020).

15. Johns Hopkins University. COVID-19 Data Repository. (2020). Available at: https://github.com/CSSEGISandData/COVID-19. (Accessed: 6th August 2020)

16. Dyer, O. Covid-19: US testing ramps up as early response draws harsh criticism. BMJ (2020). doi:10.1136/bmj.m1167

17. Boccia, S., Ricciardi, W. \& loannidis, J. P. A. What Other Countries Can Learn From Italy During the COVID-19 Pandemic. JAMA Intern. Med. (2020). doi:10.1001/jamainternmed.2020.1447

18. Centers for Disease Control and Prevention. Recommendation Regarding the Use of Cloth Face Coverings, Especially in Areas of Significant Community-Based Transmission. CDC website (2020). Available at: https://www.cdc.gov/coronavirus/2019-ncov/prevent-getting-sick/cloth-face-cover.html.

19. County of Los Angeles Public Health. Health Officer Order's Impact on Daily Life FAQs. (2020). Available at: http://www.ph.lacounty.gov/media/Coronavirus/docs/HOO/FAQSaferatWorkandCommunityOrder.pdf. (Accessed: 31st July 2020)

20. Centers for Disease Control and Prevention. Coronavirus Disease 2019 - Older Adults. (2020). Available at: https://www.cdc.gov/coronavirus/2019-ncov/need-extra-precautions/older-adults.html. (Accessed: 1st July 2020)

21. López, L. \& Rodó, X. The end of social confinement and COVID-19 re-emergence risk. Nat. Hum. Behav. (2020). doi:10.1038/s41562-020-0908-8

22. California Department of Public Health. Resilience Roadmap. (2020). Available at: https://covid19.ca.gov/roadmap/. (Accessed: 25th July 2020)

23. American Academy of Pediatrics; \& Children's Hospital Association. Children and COVID-19: State Data Report. (2020). Available at: https://downloads.aap.org/AAP/PDF/AAP and CHA - Children and COVID-19 State Data Report 7.30.20 FINAL.pdf. (Accessed: 1st August 2020)

24. US Department of State. International Travel. (2020). Available at: https://travel.state.gov/content/travel/en/international-travel.html. (Accessed: 1st August 2020)

25. Google. Covid-19 Community Mobility Reports. (2020). Available at: https://www.google.com/covid19/mobility/.

26. Wu, X., Nethery, R. C., Sabath, B. M., Braun, D. \& Dominici, F. Exposure to air pollution and COVID-19 mortality in the United States. medRxiv (2020). doi:https://doi.org/10.1101/2020.04.05.20054502

27. Ma, Y. et al. Effects of temperature variation and humidity on the death of COVID-19 in Wuhan, China. Sci. Total Environ. (2020). doi:10.1016/j.scitotenv.2020.138226 
28. Zhu, Y., Xie, J., Huang, F. \& Cao, L. Association between short-term exposure to air pollution and COVID-19 infection: Evidence from China. Sci. Total Environ. (2020). doi:10.1016/j.scitotenv.2020.138704

29. National Travel and Tourism Office. 2020 U.S. Travel and Tourism Statistics. (2020). Available at: https://travel.trade.gov/outreachpages/inbound.general_information.inbound_overview.asp.

30. The World Bank. International tourism. (2020). Available at: https:// data. worldbank.org/indicator/ST.INT.ARVL?end=2018\&start=1995\&view=chart.

31. Trading Economics. Kenya Tourist Arrivals. (2020). Available at: https://tradingeconomics.com/kenya/tourist-arrivals.

32. Wikepidia. Tourism in South Korea. (2020). Available at: https://en.wikipedia.org/wiki/Tourism_in_South_Korea\#cite_note-:0-22. (Accessed: 13th July 2020)

33. Our World in Data. Tourism. (2020). Available at: https://ourworldindata.org/tourism.

34. NBC Los Angeles. Los Angeles Reached Record Milestone of 50 Million Visitors in 2018. (2019). Available at: https://www.nbclosangeles.com/news/local/los-angeles-visitors2018/2386/\#: :text=In surpassing 50 million total,visitors (3.6 percent increase). (Accessed: 13th July 2020)

35. US Travel Association. U.S. TRAVEL AND TOURISM OVERVIEW (2019). (2019).

36. Global Tourism Forum. Kenya Tourism Sector Performance 2019. (2020).

37. Wikepidia. Tourism in New York City. (2020). Available at: https://en.wikipedia.org/wiki/Tourism_in_New_York_City.

38. Naitional Travel and Tourism Office. I-94 Arrivals. (2020). Available at: https://travel.trade.gov/view/m-2017-I-001/index.asp.

39. Backer, J. A., Klinkenberg, D. \& Wallinga, J. Incubation period of 2019 novel coronavirus (2019-nCoV) infections among travellers from Wuhan, China, 20-28 January 2020. Euro Surveill. (2020). doi:10.2807/1560-7917.ES.2020.25.5.2000062

40. Cao, Z. et al. Incorporating human movement data to improve epidemiological estimates for 2019nCoV. medRxiv (2020).

41. Bi, Q. et al. Epidemiology and Transmission of COVID-19 in Shenzhen China: Analysis of 391 cases and 1,286 of their close contacts. medRxiv (2020). doi:10.1101/2020.03.03.20028423

42. Cori, A., Ferguson, N. M., Fraser, C. \& Cauchemez, S. A new framework and software to estimate timevarying reproduction numbers during epidemics. Am. J. Epidemiol. (2013). doi:10.1093/aje/kwt133

43. Du, Z. et al. Serial Interval of COVID-19 among Publicly Reported Confirmed Cases. Emerg. Infect. Dis. (2020). doi:10.3201/eid2606.200357

44. Wallinga, J. \& Teunis, P. Different epidemic curves for severe acute respiratory syndrome reveal similar impacts of control measures. Am. J. Epidemiol. (2004). doi:10.1093/aje/kwh255

45. Prem, K., Cook, A. R. \& Jit, M. Projecting social contact matrices in 152 countries using contact surveys and demographic data. PLoS Comput. Biol. (2017). doi:10.1371/journal.pcbi.1005697 
46. ACAPS. COVID19 GOVERNMENT MEASURES DATASET. (2020). Available at: https://www.acaps.org/covid19-government-measures-dataset. (Accessed: 5th July 2020)

\section{Figures}

.
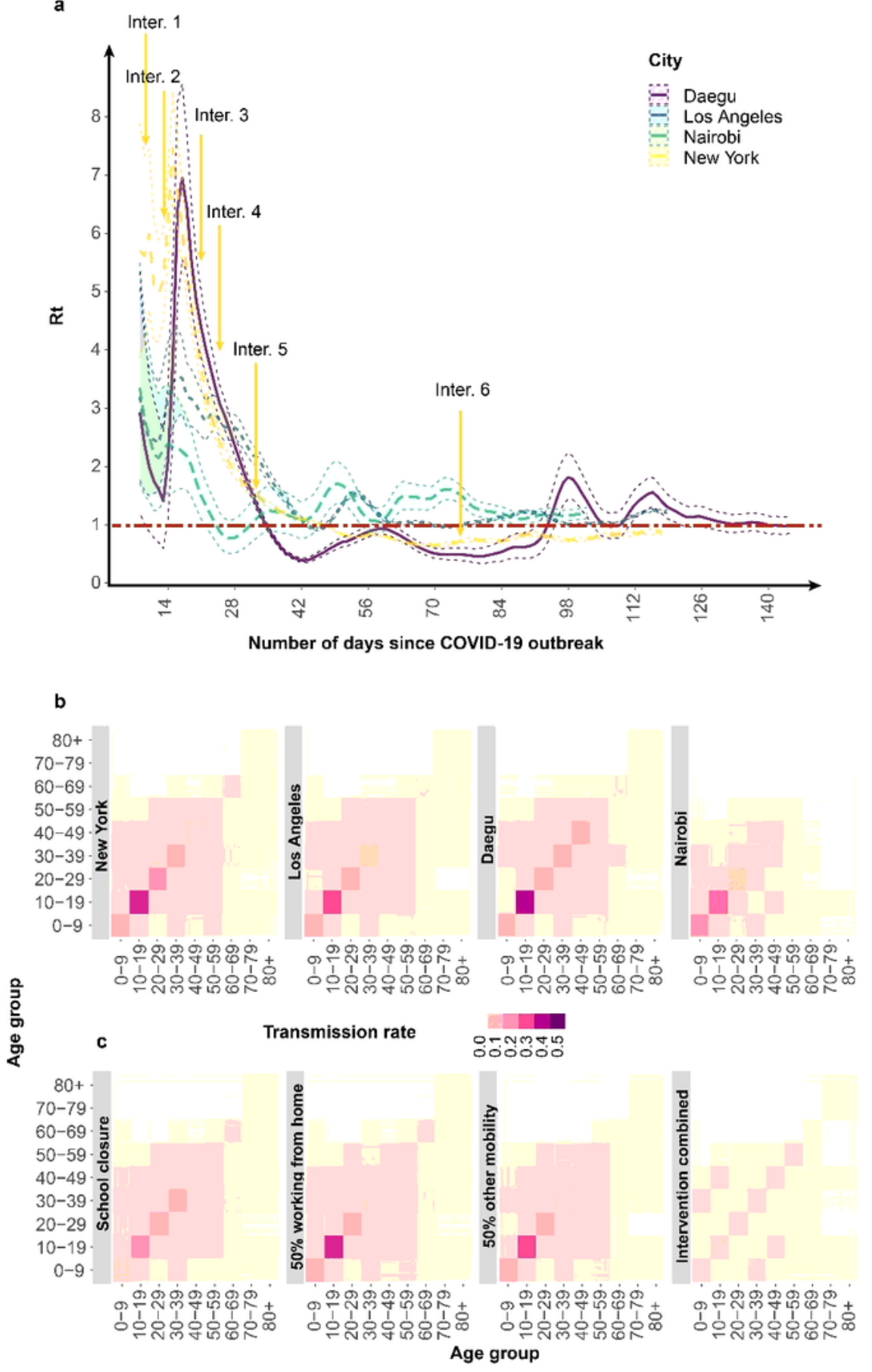

Figure 1

Page 19/25 
Rt (a) and transmission rates in New York, Los Angeles, Daegu, Nairobi (b) and counterfactual transmission rates of different interventions (c). Figure 1a, Inter. 1-6 are the interventions inserted at corresponding date in New York. Inter. 1 refers to interventions including city instruction for quarantine, hygiene and emergency announcement. Inter. 2 is school closing and working from home order. Inter. 3 and Inter. 4 are the enhanced public policy to increase social distancing and travel restriction. Inter. 5 required population to wear facemasks, while Inter. 6 started to implement open-up policies in New York. It shows that Rt showed decreased trends before intervention 6, however, the open-up interventions led to the rise of Rt afterwards. Figure 1c, Intervention combined refers to intervention package including school closure, $50 \%$ working from home, $50 \%$ other mobility reduction.
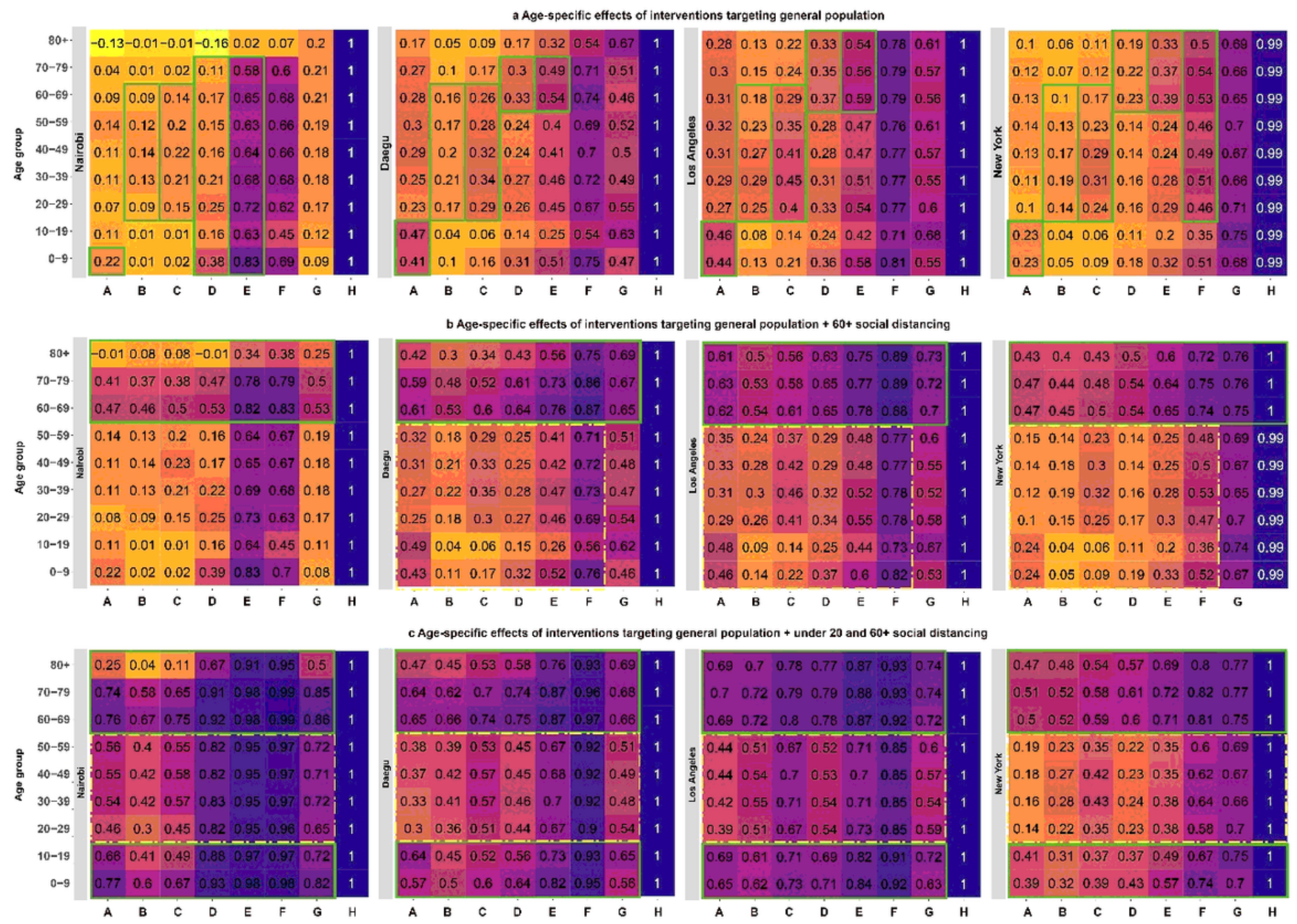

\section{Figure 2}

The proportion of avoided infected cases to the non-intervention infection in the eight interventions targeting general population, population aged under 20, and 60 and older in the four cities. The green boxes covered the population that mostly affected and yellow dashed boxes covered the population that were not targeted by social distancing but experienced the spillover effects. The social distancing strategy targeting the older population (60 and older) refers to $50 \%$ reduction in the contact interaction 
between population aged 60 and older and population under 20 years old, and also $50 \%$ reduction in the contact interaction between population aged 60 and older and population aged 60 and older. The social distancing strategy targeting young population (under 20 ) refers to $50 \%$ reduction in the contact interaction between the population aged under 20 and the population under 20 years old.

Earlier interventions in four cities

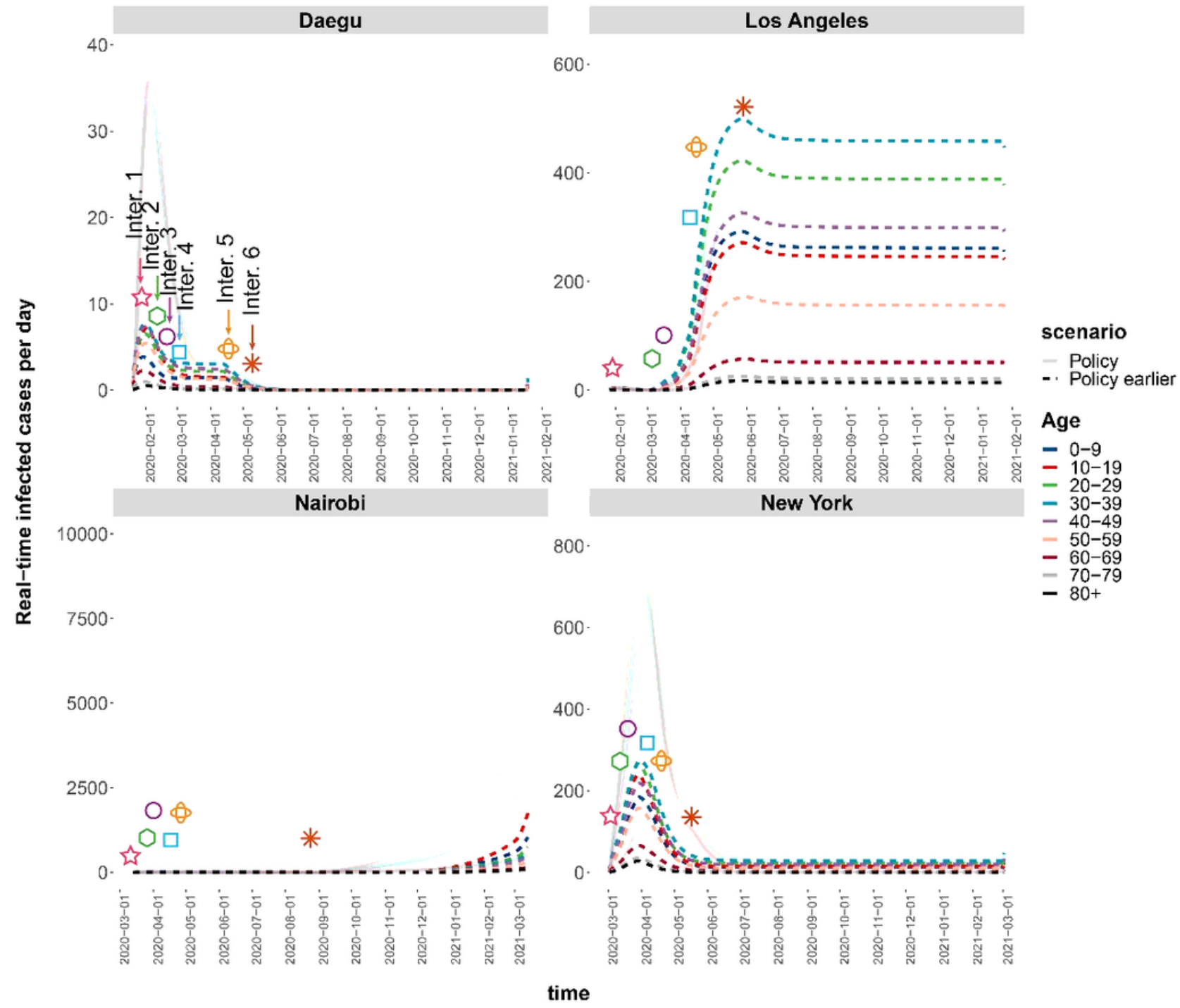

Figure 3

Age-specific effects of 1-week earlier intervention in four cities (Details of intervention data were listed in Supplementary.) 

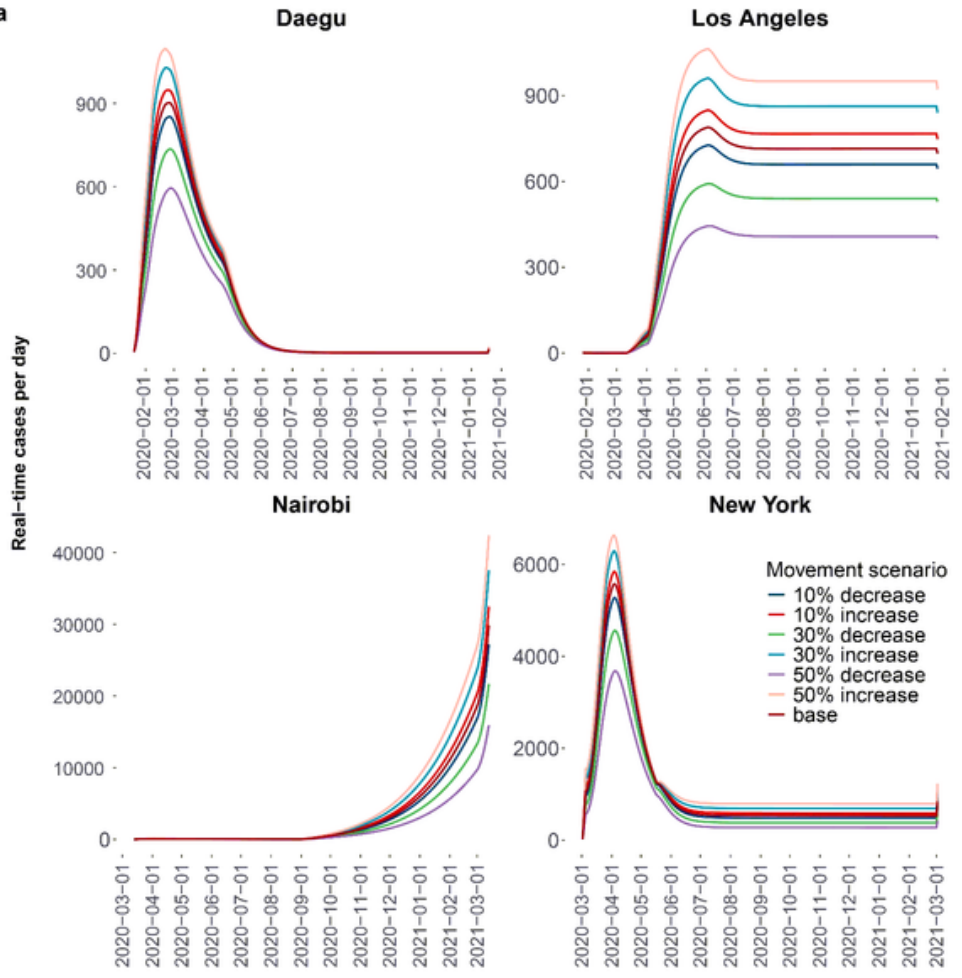

b
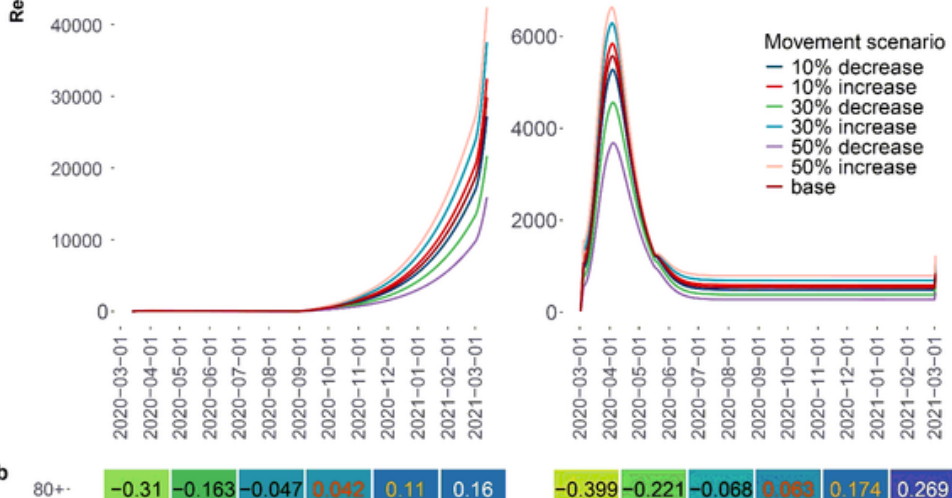

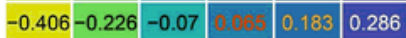

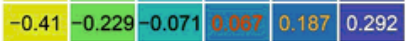
\begin{tabular}{|l|l|l|l|l|l|l|}
$60-69$. & $-0.316-0.167$ & -0.049 & 0.04 & 0.116 & 0.172 \\
\hline
\end{tabular} \begin{tabular}{|l|r|r|r|r|r|}
\hline $50-59$. & $-0.319-0.169$ & -0.05 & & 0.118 & 0.176 \\
\hline
\end{tabular}

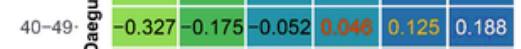
\begin{tabular}{|c|c|c|c|c|c|}
\hline $30-39 \cdot{ }^{\circ}$ & -0.33 & $-0.176-0.053$ & 0.047 & 0.127 & 0.192 \\
\hline
\end{tabular} \begin{tabular}{|l|l|l|l|l|l|l|}
\hline $20-29 \cdot$ & -0.323 & -0.172 & -0.051 & 0.0 & 0.121 & 0.181 \\
\hline
\end{tabular} \begin{tabular}{|l|l|l|l|l|l|}
\hline $10-19$. & $-0.329-0.176$ & -0.053 & & 0.128 & 0.192 \\
\hline
\end{tabular}

\begin{tabular}{|ll|l|l|l|l|l|}
\hline 을 & $0-9 \cdot$ & $-0.339-0.184$ & -0.055 & 0.15 & 0.138 & 0.211 \\
\hline
\end{tabular}

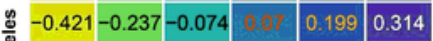
\begin{tabular}{|l|l|l|l|}
\hline 递 & $-0.432-0.246-0.078$ & 0.211 & 0.336 \\
\hline
\end{tabular}

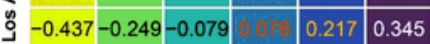

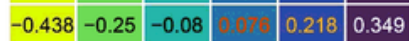

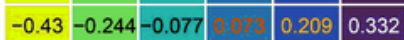

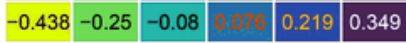

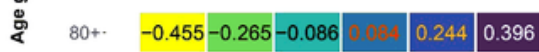
\begin{tabular}{ll|l|l|l|l|}
\hline $70-79$. & $-0.484-0.289-0.096$ & & 0.284 & 0.471 \\
\hline
\end{tabular} \begin{tabular}{|c|c|c|c|c|}
$60-69$. & $-0.488-0.292-0.097$ & & 0.289 & 0.481 \\
\hline
\end{tabular} \begin{tabular}{ll|l|l|l|l|}
$50-59 \cdot-0.487-0.291-0.097$ & & 0.288 & 0.479 \\
\hline
\end{tabular} \begin{tabular}{|l|l|l|l|l|l|}
\hline $40-49 \cdot \frac{\overline{0}}{\text { 은 }}-0.487-0.291$ & -0.097 & & 0.288 & 0.479 \\
\hline
\end{tabular}

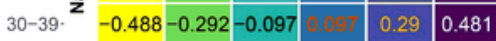
\begin{tabular}{|l|l|l|l|l|l|}
\hline $20-29-$ & $-0.486-0.291$ & -0.096 & & 0.287 & 0.476 \\
\hline
\end{tabular}

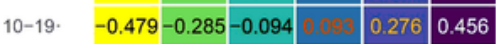

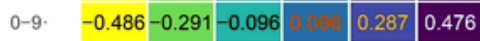

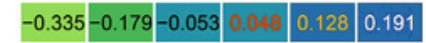
\begin{tabular}{l|l|l|l|l|}
$-0.338-0.181$ & -0.054 & & 0.132 & 0.198 \\
\hline
\end{tabular} \begin{tabular}{ll|l|l|l|}
$-0.348-0.188$ & -0.057 & & 0.142 & 0.217 \\
\hline
\end{tabular} \begin{tabular}{ll|l|l|l|l|l|}
$\times-0.364$ & -0.2 & -0.061 & & 0.158 & 0.246 \\
\hline
\end{tabular} \begin{tabular}{l|l|l|l|l|l|}
\hline & $-0.386-0.217$ & -0.068 & & 0.181 & 0.286 \\
\hline
\end{tabular} \begin{tabular}{|l|l|l|l|l|}
\hline$-0.404-0.229$ & -0.073 & & 0.199 & 0.318 \\
\hline
\end{tabular} \begin{tabular}{|l|l|l|l|l|}
\hline$-0.392-0.221$ & -0.069 & & 0.186 & 0.296 \\
\hline
\end{tabular} \begin{tabular}{|l|l|l|l|l|l|}
\hline-0.363 & -0.2 & -0.061 & & 0.157 & 0.244 \\
\hline
\end{tabular}

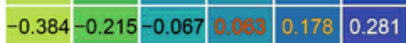

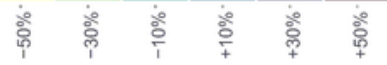

\section{Figure 4}

The sensitivity analysis of population movement on the spread of COVID-19 

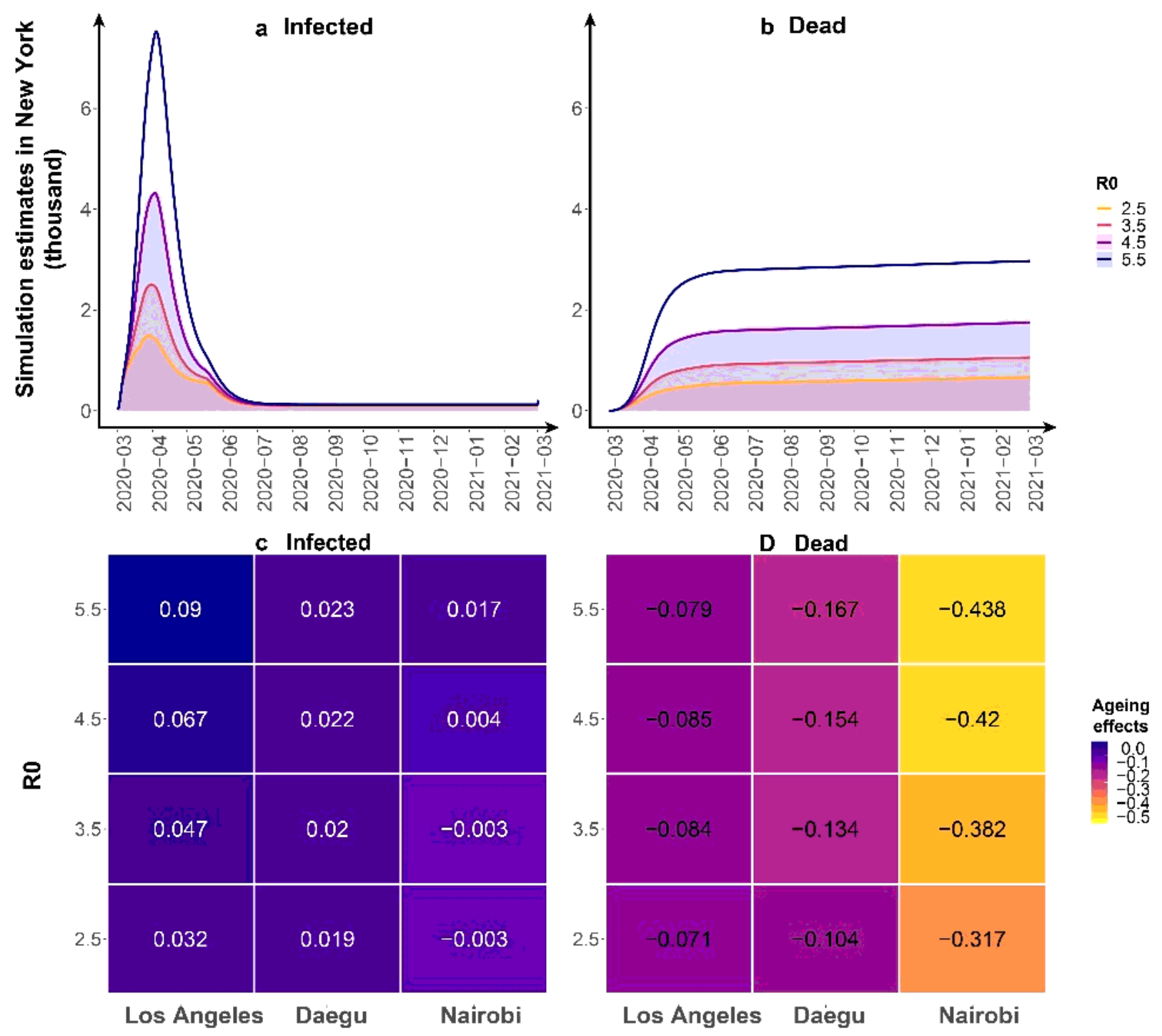

\section{Figure 5}

The effects of population age structure on the effectiveness of intervention policy and sensitivity analysis of R0. Here ageing effects are defined as follows: Ageing effects on infection = (I_Los Angeles - I_New York/I_New York) and Ageing effects on death = (D_Los Angeles - D_New York/D_New York). 


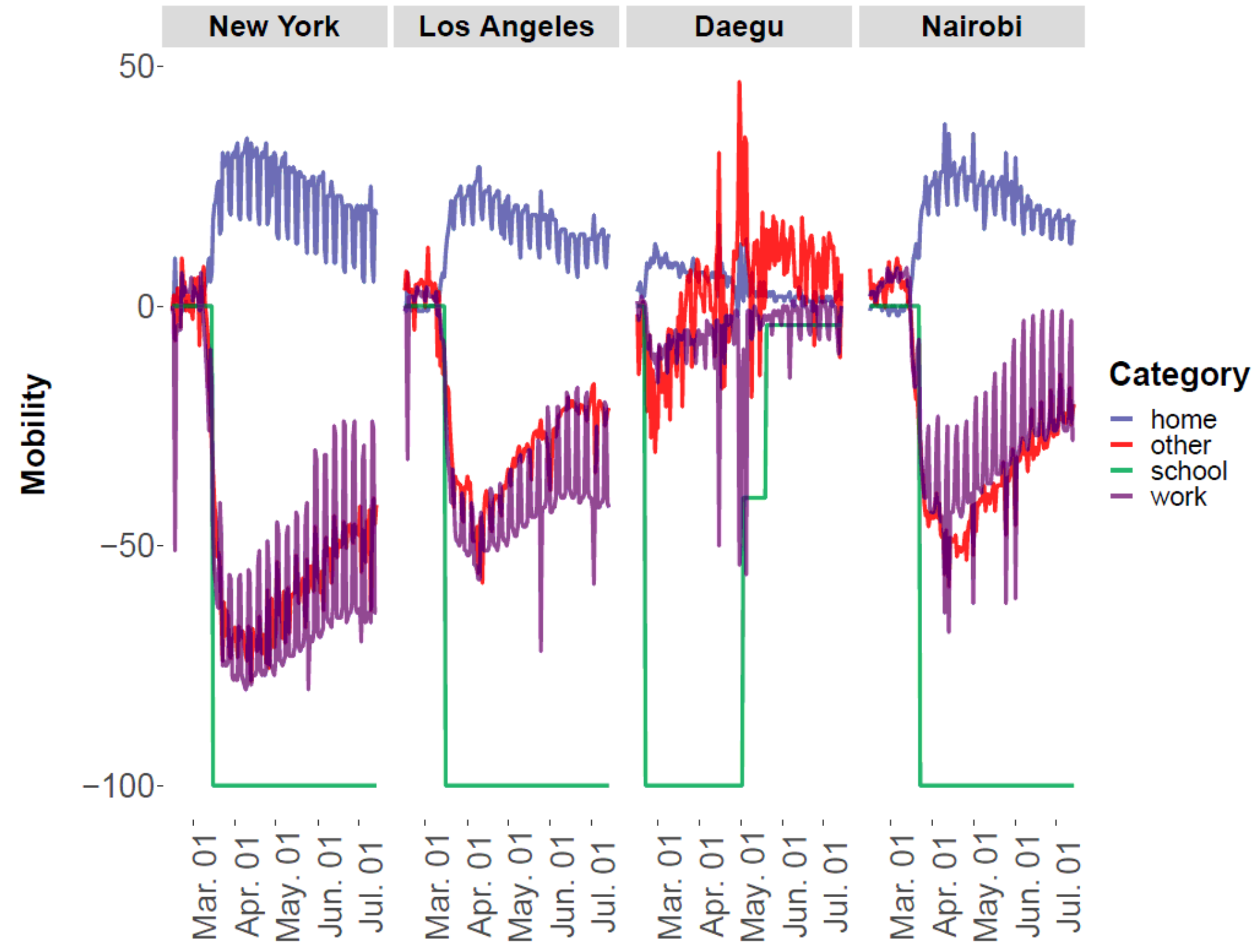

Figure 6

Mobility change in the four cities since the outbreak of COVID-19 


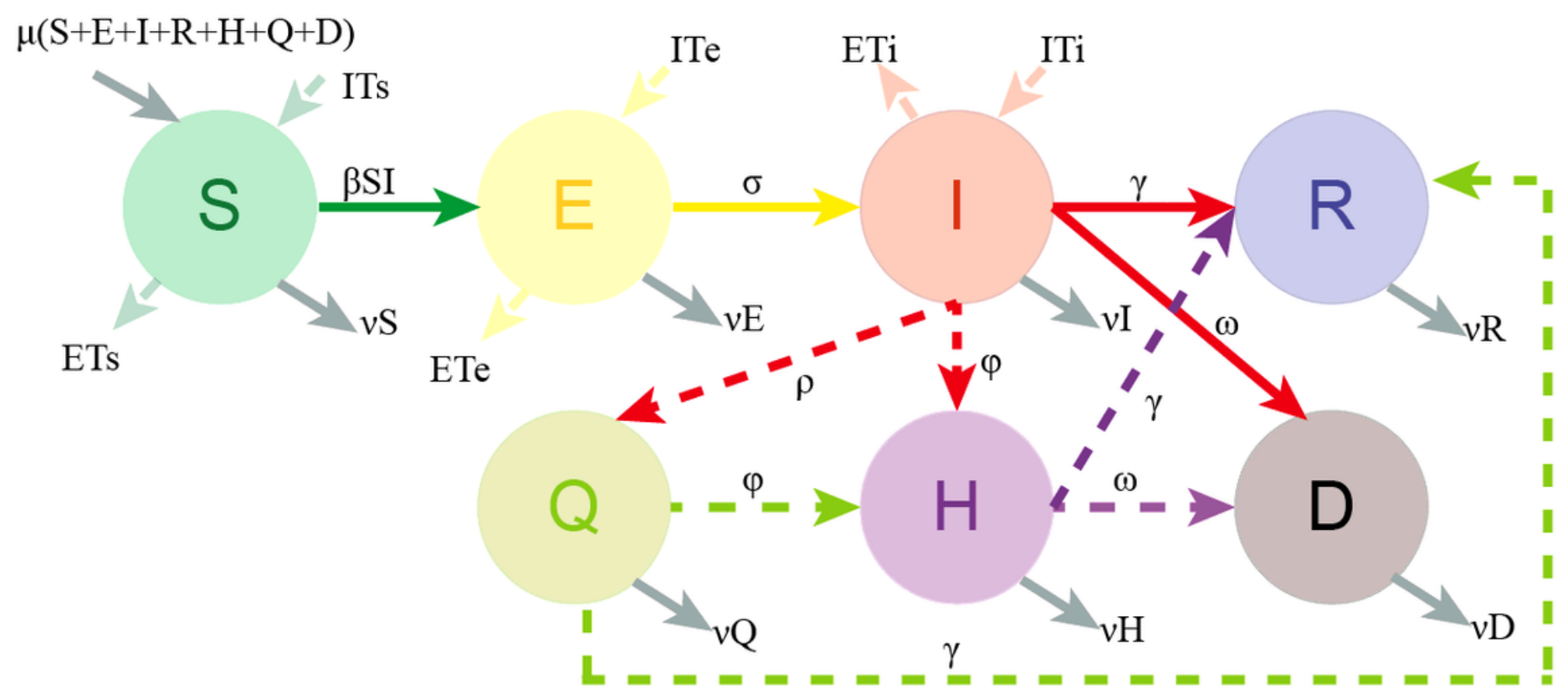

\section{Figure 7}

Schematic framework of SEIR-HQD epidemic model "S = Susceptible, refers to the full city population", "E = Exposed, refers to infected but not infectious yet", "I = Infected, refers to population who are infected and infectious", "R = Recovered, refers to the population who are recovered", "Q = Quarantined, refers to the population who are quarantined", " $\mathrm{H}=$ Hospitalized, refers to people who are hospitalized, " $\mathrm{D}=\mathrm{Dead}$, refers to the population who are dead infected". ITs and ETs refer to the imported and exported travelers who are susceptible, respectively. ITe and ETe refer to the imported and exported travelers who are exposed, respectively. ITi and ETi refer to the imported and exported travelers who are infected, respectively. $v$ is the birth rate per thousand population, $\mu$ is the death rate of population, $\beta S I$ refers to the infection force, $\sigma$ is incubation rate, $\gamma$ is recover rate, $\omega$ is the death rate of infected population, $\varphi$ is the hospitalization rate, $\rho$ is quarantine rate.

\section{Supplementary Files}

This is a list of supplementary files associated with this preprint. Click to download.

- SupportingInformation.docx 